\title{
Letter to the Editor: Symptomatic Pulmonary Embolus After Joint Arthroplasty: Stratification of Risk Factors
}

\author{
Mehmet Eroglu MD, Ihsan Senturk MD, \\ Ersin Gunay MD
}

To the editor,

e read the article by Par-
vizi et al. with great
interest [8].

Parvizi and colleagues identified the preoperative comorbidities associated with an increased risk of symptomatic pulmonary embolism (PE) after total joint arthroplasty (TJA) in a large group of patients. The authors concluded that patients with obesity, chronic obstructive pulmonary disease, atrial fibrillation, anemia, depression, or postoperative deep vein thrombosis, as well as those patients who undergo knee procedures, or

(RE: Parvizi J, Huang R, Raphael IJ, Arnold WV, Rothman RH. Symptomatic pulmonary embolus after joint arthroplasty: stratification of risk factors. Clin Orthop Relat Res. 2014;472:903-912.)

Each author certifies that he or she, or a member of his or her immediate family, has no commercial associations (eg, consultancies, stock ownership, equity interest, patent/ licensing arrangements, etc) that might pose a conflict of interest in connection with the submitted article.

All ICMJE Conflict of Interest Forms for authors and Clinical Orthopaedics and Related Research ${ }^{\mathbb{R}}$ editors and board members are on file with the publication and can be viewed on request. have a high Charlson Comorbidity Index, are at an increased risk of having a postoperative PE development. Those risk factors should be considered when deciding on postoperative anticoagulation prophylaxis. According to Parvizi and colleagues, the reasons why preoperative anemia is a risk factor for $\mathrm{PE}$ development remains unclear.

Several studies from internal medicine $[2-4,6,7]$ suggest some possible mechanisms for PE development in iron deficiency anemia (IDA). We reviewed and summarized the mechanisms to explain the association

The opinions expressed are those of the writers, and do not reflect the opinion or policy of $\mathrm{CORR}^{\circledR}$ or the Association of Bone and Joint Surgeons ${ }^{\circledR}$.

M. Eroglu MD ( $\bowtie)$, I. Senturk MD Department of Orthopaedics and Traumatology, Faculty of Medicine, Afyon Kocatepe University, Afyon-Izmir Karayolu 8. km, 03200 Afyonkarahisar, Turkey

e-mail: meroglufb@gmail.com

\section{E. Gunay MD}

Department of Pulmonary Diseases,

Faculty of Medicine, Afyon Kocatepe University, Afyonkarahisar, Turkey between IDA and thrombosis. First, iron is a crucial regulator of thrombopoiesis due to its negative feedback effect on platelet production and lower levels of iron disinhibit megakaryocyte activity [2]. These characteristics promote secondary thrombocytosis, which lead to a hypercoagulable state [4]. Additionally, when erythropoietin increases to stimulate the red cell production, it also stimulates the megakaryocyte production [3]. Second, in IDA, microcytosis causes lower red cell deformability, which increases the blood viscosity [7]. Third, when the oxygen-carrying capacity of erythrocytes decreases, anemic hypoxia may occur, especially in situations where the metabolic demands are increased. The vessels undergo autoregulatory dilatation, which can lead to a turbulent blood flow, causing more frequent contact of the platelets with the endothelial lining of the vessels [3, 6]. Fourth, platelets may become hyperresponsive in anemic states due to the increased levels of erythropoietin. The abnormal platelet count and function observed in IDA can promote thrombus formation, especially in the setting of an 


\section{Letter to the Editor}

underlying atherosclerotic disease $[2,3]$. Fifth, the decrease in antioxidant defense may cause increased oxidant stress, which could result in platelet aggregation [2]. And finally, acute bleeding raises platelet adhesiveness and lowers fibrinolytic activity, which leads to intravascular thrombogenesis [7].

As would be expected, other forms of anemia such as sickle cell disease, thalassemia or autoimmune hemolytic anemia may also cause both arterial and venous thrombosis $[1,5,9]$. After considering the possible mechanisms, the question, "Should we better detect the cause of anemia and treat it firstly prior to TJA?" emerges and needs further investigation.

\section{References}

1. Ataga KI, Cappellini MD, Rachmilewitz EA. Beta-thalassaemia and sickle cell anaemia as paradigms of hypercoagulability. Br J Haematol. 2007;139:3-13.

2. Franchini M, Targher G, Montagnana M, Lippi G. Iron and thrombosis. Ann Hematol. 2008;87:167-173.

3. Habis A, Hobson WL, Greenberg R. Cerebral sinovenous thrombosis in a toddler with iron deficiency anemia. Pediatr Emerg Care. 2010;26:848-851.

4. Hartfield DS, Lowry NJ, Keene DL, Yager JY. Iron deficiency: a cause of stroke in infants and children. Pediatr Neurol. 1997;16:50-53.

5. Hendrick AM. Auto-immune haemolytic anaemia-a high-risk disorder for thromboembolism? Hematology. 2003;8:53-56.

6. Nicastro N, Schnider A, Leemann B. Iron-deficiency anemia as a rare cause of cerebral venous thrombosis and pulmonary embolism. Case Rep Med. 2012;2012:497814.

7. Ogata T, Kamouchi M, Kitazono T, Kuroda J, Ooboshi H, Shono T, Morioka T, Ibayashi S, Sasaki T, Iida M. Cerebral venous thrombosis associated with iron deficiency anemia. $J$ Stroke Cerebrovasc Dis. 2008;17: 426-428.

8. Parvizi J, Huang R, Raphael IJ, Arnold WV, Rothman RH. Symptomatic pulmonary embolus after joint arthroplasty: stratification of risk factors. Clin Orthop Relat Res. 2014;472: 903-912.

9. Stein PD, Beemath A, Meyers FA, Skaf E, Olson RE. Deep venous thrombosis and pulmonary embolism in hospitalized patients with sickle cell disease. Am J Med. 2006;119:897 e897-811. 